\title{
Corrigendum: Bosonic coherent motions in the Universe
}

\author{
Jihn E. Kim ${ }^{1,2 *}$, Yannis K. Semertzidis ${ }^{3,4}$ and Shinji Tsujikawa ${ }^{5}$ \\ 1 Department of Physics, Seoul National University, Seoul, South Korea \\ ${ }^{2}$ Department of Physics, Kyung Hee University, Seoul, South Korea \\ ${ }^{3}$ Center for Axion and Precision Physics Research, Institute for Basic Science, Daejeon, South Korea \\ ${ }^{4}$ Department of Physics, Korea Advanced Institute of Science and Technology, Daejeon, South Korea \\ ${ }^{5}$ Department of Physics, Faculty of Science, Tokyo University of Science, Tokyo, Japan \\ ${ }^{*}$ Correspondence: jihnekim@gmail.com
}

Edited and reviewed by:

J. W. F. Valle, National Council for Scientific Research, Spain

Keywords: axion, cold dark matter, dark energy, cosmological constant, global symmetry, unification of forces, inflation

\section{A corrigendum on}

Bosonic coherent motions in the Universe by Kim, J. E., Semertzidis, Y. K., and Tsujikawa, S. (2014). Front. Phys. 2:60. doi: 10.3389/fphy.2014.00060

Due to the corrections in the tables of Kim (2014), published in Physics Letters B [1], Figure 4 of Kim et al. [2] is hereby updated to the version below.

\section{REFERENCES}

1. Kim JE. Calculation of axion-photon-photon coupling in string theory. Phys Lett B (2014) 735:95-100. doi: 10.1016/j.physletb.2014. 06.021

2. Kim JE, Semertzidis YK, Tsujikawa S. Bosonic coherent motions in the universe. Front Phys. (2014) 2:60. doi: 10.3389/fphy.2014.00060

Conflict of Interest Statement: The authors declare that the research was conducted in the absence of any commercial or financial relationships that could be construed as a potential conflict of interest.

Received: 08 January 2015; accepted: 19 January 2015; published online: 06 February 2015.
Citation: Kim JE, Semertzidis YK and Tsujikawa S (2015) Corrigendum: Bosonic coherent motions in the Universe. Front. Phys. 3:4. doi: 10.3389/fphy. 2015.00004

This article was submitted to High-Energy and Astroparticle Physics, a section of the journal Frontiers in Physics.

Copyright (c) 2015 Kim, Semertzidis and Tsujikawa. This is an open-access article distributed under the terms of the Creative Commons Attribution License (CC BY). The use, distribution or reproduction in other forums is permitted, provided the original author(s) or licensor are credited and that the original publication in this journal is cited, in accordance with accepted academic practice. No use, distribution or reproduction is permitted which does not comply with these terms. 


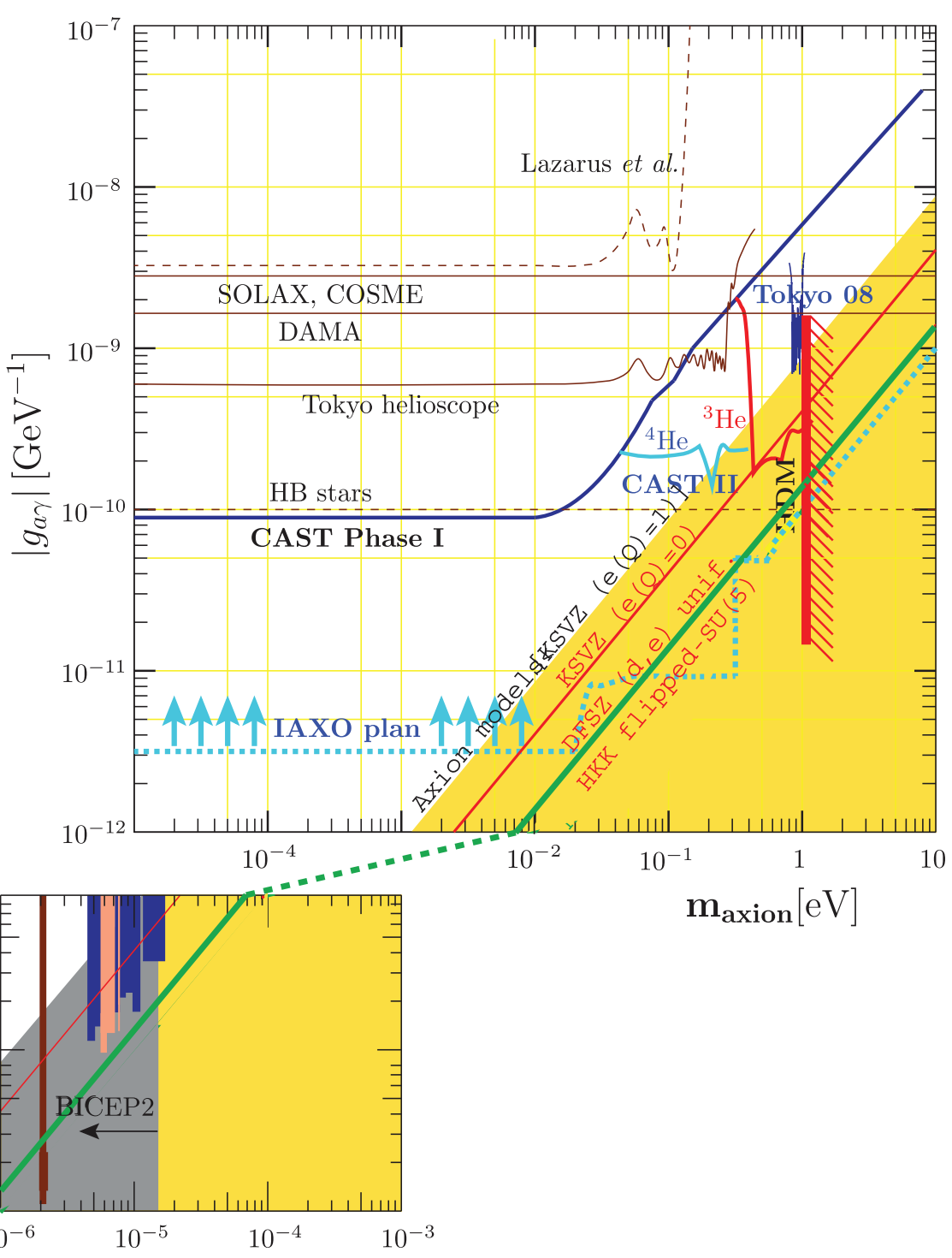

FIGURE 4 | 